\title{
Correction to: Plant diversity and density in cocoa-based agroforestry systems: how farmers' income is affected in the Dominican Republic
}

\author{
M. Notaro (i) C. Gary • O. Deheuvels
}

Published online: 18 March 2020

(C) Springer Nature B.V. 2020

\section{Correction to: Agroforest Syst}

https://doi.org/10.1007/s10457-019-00472-7

In the original publication of the article, three equations under section "Assessment of economic performances" were published incorrectly. The corrected equations are given below:

- The annual income from cocoa: $C I=y C * p C$,

- The annual income from fruits: $O P I=$ $\sum_{i=1}^{N b P S} y O P S_{i} * p O P_{i}$,

The original article can be found online at https:// doi.org/10.1007/s10457-019-00472-7.

M. Notaro $(\varangle) \cdot$ C. Gary · O. Deheuvels

System, CIRAD, CIHEAM-IAMM, INRA, Montpellier

SupAgro, Univ Montpellier, Montpellier, France

e-mail: martin.notaro@cirad.fr

O. Deheuvels

World Agroforestry Centre, Regional Office for Latin

America, Lima, Peru

O. Deheuvels

CIRAD, UMR System, Lima 12, Peru
- The value of self-consumption: $V D C=$ $\sum_{i=1}^{N b P C} y O P C_{i} * p O P_{i}$,

The original article has been corrected.

Publisher's Note Springer Nature remains neutral with regard to jurisdictional claims in published maps and institutional affiliations. 